\title{
MÁSCARAS MEXICANAS EN LA POESÍA DE CERNUDA Y MORENO VILLA: QUETZALCÓATL Y XOCHIPILLI
}

1. En la vida y en la obra de Luis Cernuda y José Moreno Villa se abren dos espacios mexicanos. Las circunstancias los llevaron a México, donde amaron, crearon y murieron. De esa vivencia quedan huellas escritas. En Cernuda, pocas pero profundas: las delicadas prosas poéticas de Variaciones sobre tema mexicano (1952). Moreno Villa, polifacético, ha dejado innovadores estudios sobre arte mexicano, agudas observaciones sobre costumbres y lenguaje, una autobiografía y un grupo de poemas ${ }^{1}$.

Los aconteceres históricos del primer tercio de siglo habían propiciado un acercamiento entre España y México. Recuérdese el protagonismo de Valle-Inclán durante la conmemoración del Centenario (1921); y a Alfonso Reyes, Martín Luis Guzmán, Genaro Estrada, Torres Bodet, el jovencísimo Octavio Paz, codeándose con los intelectuales españoles. Entre éstos, por ejemplo, Alberti ("El indio", 13 bandas y 48 estrellas [1935]) y Antonio Machado ("A Méjico", soneto) poetizan sobre dicho país. Su laudable intención extra-poética no salva del todo estos poemas, circunstanciales, descartables. Pertenecen a esa poesía civil contra la cual se pronuncia Cernuda: "Arte y política no tienen círculos concéntricos de acción; se cruzan a lo más, y no puede identificárseles [.. ] La obra artística que no resista a la desaparición de la época y sociedad en que apareció, no merece que como tal obra de arte se la considere". ("Poesía popular" [1941], en $P y L$, p. 21$)^{2}$.

${ }^{1}$ Véase mi "Presencia de México en tres escritores españoles: Jarnés, Moreno Villa, Sender", CH(3), pp. 77-88.

${ }^{2}$ Las siglas usadas para obras de Cernuda son: PyL (Poesía y literatura, I y II, Seix Barral, Barcelona, 1975); HL ("Historia de un libro", en la misma ed.); PPLI (Pensamiento poético en la lírica inglesa, Imprenta Universitaria, Méxi$\mathrm{co}, 1958)$. 
2. Las "máscaras mexicanas" del título no tienen que ver cor la política, el folklore, la arqueología o la psicología cultural. Sor signos y función íntimamente ligados al sentir y quehacer poéti eos de Cernuda y de Moreno Villa. Los poemas que recurren : ellas, y a la vez las constituyen, son hitos destacados en la obr: poética de ambos, merecedores por tanto de particular atención

Cernuda, crítico exigente consigo mismo, dice de Como quie espera el alba (1947): "es quizás una de las colecciones de mis ver sos donde más cosas hay que prefiero" (HL, p. 202). Se inscrib en la segunda etapa cernudiana, iniciada con su poemario $L a$ nubes (1943). En ella hay poemas escritos en pleno fragor de 1 guerra civil española y la mundial. Como quien espera el alba agrup treinta poemas; uno lleva por título "Quetzalcóatl". En una cc lección donde abundan poemas largos, lo es el más, con 116 ves sos también largos. Tal vez no sea casualidad que ocupe un luge casi central en la colección. Y sin duda no lo es que saliera a ] luz primero en El Hijo Pródigo, de la capital mexicana (9 de d ciembre de 1943). Cronológicamente se retrotrae, pues, a $L_{1}$ nubes. De los poemas de Como quien espera el alba, "Quetzalcóatl cuadra en hechura, talante y tono con los mejores de Las nub (por ejemplo, "Lázaro") así como con algunos de los más logr dos poemas del Cernuda futuro (por ejemplo, "Luis de Bavie: escucha Lohengrin"). Sin embargo, la atención que se le ha di pensado ha sido de pasada ${ }^{3}$. Es "Quetzalcóatl" uno de los p cos poemas cernudianos - apenas una docena - titulados con 1 nombre propio. En éste se dan sincretismo y disemia: mito azt ca y, a la vez, el personaje histórico que según los indígenas encarnó, Cortés. Significativamente, una matización alusiva $\mathrm{F}$ recida, aunque de diferente registro, se encuentra ya en el títc mismo, tan coloquial, de la colección. La expresión "como qui espera" refleja ambivalencia: ¿se trata de esperanza verdader de una evasiva; corresponde a una realidad virtual o es tan st deseo, para decirlo con la designación que dio Gernuda al cc junto de su poesía? Enmascarada en este poema está parte de respuesta; proponemos una lectura que sea desenmascararmi to, revelación.

${ }^{3}$ La crítica apenas si se detiene en "Quetzalcóatl". Aunque con resu dos diferentes a los de este trabajo, dos excepciones muy de tener en cuc son: Jenaro Talens, El espacio y las máscaras. Introducción a la lectura de Cerni Anagrama, Barcelona, 1975, pp. 120-121, 264, 295-296; y Salvador J1 nez-Fajardo, Luis Cernuda, Twayne, Boston, 1978, pp. 85-87. 
"Quetzalcóatl" "4 está estructurado en 16 unidades estróficas, de cinco a nueve versos. Su estructura interna, más sutil y trabada a la vez que de mayor significación, combina magistralmente características de monólogo dramático y pieza musical. Comienza con un breve y simple enunciado, a modo de acorde, que el poema desarrollará en dos movimientos. "La música -dice Cernuda- ha sido para mí, aún más quizás que las otras artes, la que prefiero después de la poesía"' (HL, p. 203). Tres elementos conforman dicho enunciado: un sujeto en primera persona ("Yo"); otro en segunda del plural, presuntos oyentes/lectores (vosotros); y un tercer elemento: personas o sucesos aludidos.

Desde el comienzo ese "yo" se adueña del discurso con una voz testimonial, autorizada, cronística: "Yo estaba allí". La segunda persona involucra a los lectores: "no me preguntéis"; ellos/nosotros como destinatarios del tercer elemento del enunciado: lo relatado. El anonimato en que voluntariamente se oculta el hablante ("No importa el nombre") antes le gana que resta representatividad: origen miserable en una aldea del Viejo Mundo; el atractivo de las Indias; cruce del océano; encuentro con Cortés. El ritmo rápido de este primer movimiento del poema apenas si se remansa en un interrogante ("¿Quién le dio al fango un alma?') y una contemplación del cielo castellano. Según el enunciado, lo que ese "yo" va a atestiguar es algo sobrenatural, un "milagro" cuyo autor está aureolado de misterio: "no me preguntéis/de dónde o cómo vino". La reticencia del hablante remite a un pasado impreciso, como el del mito o la leyenda.

La estrofa quinta se corresponde con la primera, pero va más adelante. Aquel "yo" oscuro y anónimo se instala en el tiempo y en la historia al presentarse junto a un personaje y hechos reconociblemente históricos: Cortés y la conquista, calificada de "hazaña". La cuestión ética, Cortés como "demonio o ángel”, la deja el hablante a unos tácitos interlocutores: "como queráis". Para él, Cortés fue "sólo un hombre/tal manda Dios, apasionado y duro". Lo que parecía sobrenatural, milagroso es ahora hazañístico, humano. La posible dimensión mítica de Cortés y su empresa, su identificación con el mito de Quetzalcóatl, se someten

${ }^{4}$ Cito por Luis Cernuda, Poesía completa, Barral, Barcelona, 1977. Esta versión mejora la primera, publicada en El Hijo Pródigo (México, 1943, 152154). "Quetzalcóatl" no figura en las selecciones y antologías de Cernuda que conozco, salvo la de Philip Silver, quien sagazmente la incluye en la suya, Luis Cernuda, Antología poética, Alianza Editorial, Madrid, 1975. 
a una perspectiva temporal, histórica y, por ende, desmitificadora. Lo contrario del mitopoetizar.

En las estrofas 6-9 el "yo", pluralizado, se generaliza: "nosotros" son quienes cruzan el mar, quienes contemplan la ciudad deseada. Con una diferencia: como inicialmente respecto a los lectores, el "yo" se privilegia en cuanto a sus compañeros. A éstos los mueve "la ambición de riqueza y poderío"; a aquél lo singulariza un anhelo sin fin, aun cuando la certidumbre de su finitud física queda expresada en lenguaje muy directo: "Frente al afán de ver, de ver con estos ojos/que ha de cegar la muerte, lo demás: ¿qué valía? [..] Realidad fabulosa como leyenda alguna/allá nos esperaba'.

Con la estrofa 8 concluye la primera mitad del poema. Su proceso, como el de la Conquista, ha sido en general ascendente; predomina un tono afirmativo, entusiasta. Al mismo tiempo, va configurándose una línea mediativa. Al ya señalado "¿Quién le dio al fango un alma?" (estrofa 1), sigue la "lección digna de' alma" (estrofa 2) que imparte al niño el cielo castellano. Des. pués, al alejarse el protagonista de su patria ("madrastra fuera que no madre, y aún la quise"') la travesía marítima se le apare. ce, en retrospección, premonitoria de su último destino: "Co meneé entonces a morir, mas era joven/y en ello no pensé, dán dolo al olvido",

El segundo movimiento del poema comienza en la estrofa 9 El tono se hace acusatorio, grave, desilusionado. Ciertas son la crueldades cometidas, "mas vencimos y nadie hizo otro tanto", Se increpa a los presuntos oyentes/lectores: "ya sé lo que decís el horror de la guerra/mas lo decís en paz, y en la guerra callái con mansedumbre". Las conquistas se desvanecen como "casti llos en el aire". Si en la estrofa 3 el hablante había comparad el descubrimiento con "un poeta que regala su propio sueño $\mathrm{V}$. vo", se inicia aquí un contrapunto que gradualmente intensific su gravedad. Primero, la paráfrasis de la famosa elegía garcili siana: las conquistas se desvanecen como "castillos en el aire, $n$ bien ganados cuando ya perdidos" (estrofa 10). A continuació (estrofa 11), en poética transposición, un enlace velado con biografía del poeta renacentista: ¿Hubo algún Garcilaso que n piedra/[...] hundiera bruscamente en el fondo de la muerte? La categórica respuesta, armonizada, aporta un eco bíblico: "] reino del poeta tampoco es de este mundo".

La estrofa que sigue (12) capta un instante de exaltación: entrada en la capital azteca. Su localización en el poema se c 
rresponde con la de la estrofa 4 del primer movimiento, pero contrastándola. En aquélla el viaje marítimo ocultaba un desasimiento definitivo, un alejarse que sugiere el morir. En ésta, un acercamiento y culminación deslumbrantes mas ilusorios. Mito e historia se conjuntan. El cortejo de Moctezuma "onduló como una serpiente de bronce y diamante", atributos de firmeza y brillantez y al propio tiempo algo huidizo. Gloriosa como es, la visión de la ciudad reflejada en el lago es "como un sueño". La brevedad de ese momento se plasma en el doble pretérito, "estuve", "vi", en vez de la duración sugerida con el imperfecto y el pretérito enunciatorios (estrofa 1): "yo estaba", "estuve yo". La textura de la estrofa que sigue (14) ha ganado en delicadeza con cambios efectuados en la primera versión publicada: las exclamaciones del primer miembro estrófico han sido eliminadas y dos estrofas se han fundido en una (véase "Apéndice"). Estridencia y distancia quedan suprimidas. Moctezuma es "un pobre rey", acentuándose su condición fugaz, frágil con la aposición "golondrina rezagada [...] mojada y aterida el ala ya sin fuerza". Aunque aparentemente contrasta con el Cortés de la estrofa quinta, "duro,/temple de diamante", el destino final los aúna: "Cuando él [Cortés] se abandonó también Dios le abandona". "Milagro", "hazaña", "leyendas", como el mito, como el hombre, quedan finitamente asentados en el tiempo.

La actitud meditativa y el tono elegíaco van imponiéndose con un lenguaje llano, hablado, con una dicción ajustada, sin elevaciones excesivas ni decaimientos. Como dice Cernuda del ideal de Wordsworth, "una dicción poética no inventada a capricho por el poeta, sino imitada del lenguaje real, del lenguaje hablado; pero no de todo lenguaje hablado, simplemente, sino de aquel que, en circunstancias extraordinarias, dicta al hombre su emoción propia" ('PPLI, p. 46) 5 . Si las pasadas "victorias y derrotas" perduran es tan sólo arraigadas en el perecedero recordar

${ }^{5}$ Ya en 1949 había observado Luis Felipe Vivanco esta cualidad cernudiana: "He leído el libro de Cernuda Como quien espera el alba. ¡Qué poesía más natural y más honda! Me siento más cerca de él -aunque no de su última actitud poética - que de ningún otro poeta de su promoción. ¡Cómo ha conseguido el verso que casi no es verso! ¡Cómo no cansa, cómo nos lleva sin artificio, sin forzar la voz! Y qué terrible su voz sin tremendismo", Diario: 19461975, Taurus, Madrid, 1983, pp. 56-57. El dato es además curioso porque adelanta en una decena de años el que Silver (véase en Antología poética de Cernuda, p. 7), supone, 1958, que la poesía de Cernuda "empezó a circular clandestinamente en España"'. 
del "yo". Único sobreviviente, se pregunta: "¿Quién venció a quién?" (estrofa 15). El protagonista se contempla "solo, pobre/ tal vine", mas ahora no aguarda ilusionado un comienzo sino un "fin sin temor y sin prisa". La pregunta rechazada al principio ("'no me preguntéis/de dónde o cómo vino") tiene respuesta en una imagen totalizadora, de gran calidad poética, en la cual solera y originalidad van juntas: "Del viento nació el dios y volvió al viento/que hizo de mí una pluma entre sus alas". Aquel acorde del comienzo, afirmativo y rotundo, está sustituido por un no menos rotundo epifonema de cariz completamente opuesto: "Oh tierra de la muerte, ¿dónde está tu victoria?" Como en su antecedente bíblico (cf. Corintios, I, 15, 54-55), la pregunta queda sin respuesta directa. El propio Cernuda dijo que de la lectura de la Biblia en traducción inglesa "quizás deba quedar huella, entre otros versos, en algunos de los de Como quien espera el alba": $(H L$, p. 203). Pero antes que recurrir a una respuesta exterior a poema, proponemos una inmanente, de mayor validez herme néutica.

A lo largo del poema hay una gama de alusiones a aspecto terráqueos: "fango", "páramo", "arenal", "tierra nueva" "tierra", "cimas", "polvo", "tierra", "suelo". Dijérase que e apóstrofe "Oh tierra de la muerte", culminando esa gradació1 alusiva, le da un valor temático exclusivo, fatalista. Pero acompa sadas con ellas hay otra serie de alusiones a algo no concluyente definitivo, fijo: "mar de sangre", "agua", "abismo atlántico" "masa de agua", "mar", "lagos profundos", "masa nevada", "agua áurea de las lagunas". Estas alusiones, sugerentes de fluj dez, desembocan en la resonancia del interrogante final: "¿dór de está tu victoria?" El apóstrofe se asordina, y el oyente/lectc puede preguntarse, como aferrado a una última esperanza (¿cc mo el quien espera el alba del título del poemario?) si algo se sa vará de tan aniquilador crescendo. Quizás la obra de arte, el por ma, signo de rotación de que habla Octavio Paz, sea lo qu resista los embates del tiempo, perdurando a través de múltiplı lectores y sucesivas lecturas.

Para aquilatar mejor la elevada calidad artística de "Quetza cóatl" basta compararlo con otros poemas cernudianos. "Ur nia", de la misma colección, se nos distancia con su dependenc en lo mitológico. Otro posterior, "El elegido" (Con las horas cont das), retoma el tema azteca; desarrollado en torno al sacrificio , un guerrero joven y hermoso resulta, empero, un tanto unívo y estático. $\mathrm{O}$ bien piénsese en el poema de Archibald MacLei 
Conquistador (1932), cuyos instantes líricos están como sofocados bajo una preponderancia épico-narrativa ${ }^{6}$. Y también en el fallido intento mitopoético, con acompañamiento de notas aclaratorias, de Agustí Bartra, Quetzalcóatl, escrito entre 1957-1959.

El propio Cernuda ha explicado su poético hacer a partir de los años de Las nubes y Como quien espera el alba, tratando, dice,

de que el proceso de mi experiencia se objetivara, y no deparase sólo al lector su resultado, o sea, una impresión subjetiva [...] Algo que aprendí de la poesía inglesa, particularmente de Browning, fue el de proyectar mi experiencia emotiva sobre una situación dramática, histórica o legendaria $[\ldots]$ para que así se objetivara mejor tanto dramática como poéticamente (HL, p. 201).

Uno de los ejemplos que da es el poema "Quetzalcóatl". En Ocnos (ed. 1963) hay constancia del interés poético que los mitos clásicos tuvieron para Cernuda ("El poeta y los mitos"). El mito azteca fundido con una desmitificada proyección histórica constituye en "Quetzalcóatl" una máscara y signo poéticos en que la intensidad lírica del poeta sevillano podrá objetivarse, generalizarse, perdurar.

\section{En 1914 escribe Moreno Villa a Unamuno:}

Yo, por mí, le digo que no tengo por más poética que otra ninguna cosa de nuestros mundos - externo e interno-. Escribo con gran expontaneidad [sic], lo cual quiere decir que si me expreso vagamente respondo a la realidad interna mía. Dentro de la vaguedad del poema veo con gran nitidez su médula, la palpo y la huelo; ahora bien, no sé si ese sentimiento, claro en su fondo y velado en su forma, logra adentrarse en los demás?

${ }^{6}$ A saber si Cernuda habría conocido el poema de MacLeish, así como la obra de John H. Cornyn, The Song of Quetzalcoatl (1926), a la cual remite el poeta norteamericano en nota preliminar.

7 Véase esta carta, junto con otras, en mi "De Moreno Villa a/y Unamuno", en Historia, literatura, pensamiento. Estudios en Homenaje a María Dolores Gómez Molleda, Universidad, Salamanca, 1990, t. 1, pp. 81-96. El estudio de José Francisco Cirre, La poesia de José Moreno Villa, Ínsula, Madrid, 1962, continúa vigente y a él me remito. Complementos recientes y valiosos son los siguientes: el libro de Eugenio Carmona Nieto, sobre la plástica, José Moreno Villa y los orígenes de las vanguardias artísticas en España (1909-1936), Universidad, Málaga, 1985; el ensayo de BiruTÉ CipljausKaité, sobre la poesía, "Los "cuadros cubistas» de José Moreno Villa", en Studies in Honor of Gustavo Correa, eds. Charles B. Faulhaber, Richard P. Kinkade, \& T. A. Perry, Scripta Hu- 
La sinceridad y honestidad características de Moreno Villa resaltan en la cita. Por añadidura, pone de manisfiesto las pautas fundamentales de su poética. Los cambios en su poesía no responden a modas pasajeras, algo que Antonio Machado destacó en "Reflexiones sobre la lírica"8. Trátase de una búsqueda mantenida de la expresión que mejor corresponda a las cambiantes circunstancias por las que pasa el yo, que mejor convenga a la dinámica relación entre el vivir y el crear, un anhelo, en suma, de autenticidad.

Como se echa de ver en la precitada carta, el problema seña. lado por Cernuda en cuanto a la comunicabilidad del sentimien. to poético, y el recurrir a la objetivación para lograrlo, se k planteó también, consciente y más tempranamente, Moreno Vi lla. Y si Cernuda se esfuerza por llevar a su poesía un lenguaj، hablado, Moreno se expone - con éxito- a la expresión directa a inesperados y atrevidos quiebros antirretóricos. Hace poco años (Diario 16, Madrid, 16 de abril, 1987) ha recordado Octavi Paz la opinión asentada veinte años atrás en su magistral ensay sobre Cernuda, "La palabra edificante" (1967): "La verdad e que el único poeta español moderno que ha usado con natural: dad el lenguaje hablado es el olvidado José Moreno Villa. (F único y el primero: Jacinta la pelirroja se publicó en 1929)'.

En 1949 aparece una antología poética de Moreno Villa, $L$ música que llevaba. En vez de la acostumbrada disposición cronoli gica de los textos, figuran en cabecera los más recientes, escritc en América entre 1939-1947. Cierra esta sección un grupo c poemas con el título de "Canciones a Xochipili [sic] dios de 1: flores". Este dios menor azteca, que el poeta califica de portes toso, es el creador de las flores y dios de los juegos, de la danz. del verano y del amor. En su estudio sobre Lo mexicano en las an plásticas (1948) Moreno también destaca, ilustrándola, la "se: sualidad despierta" de esta deidad. Lo paradójico es que es creador de las flores destruye, comiéndoselas, sus propias ere

manistica, Potomac, MD, 1986, pp. 47-57; el hermoso volumen Moreno Vit Iconografía, F. C. E., México, 1988; y la ya merecida puesta al día en los es dios sobre el poeta malagueño llevada a cabo con motivo de su centenar José Moreno Villa en el contexto del 27. Actas del I Congreso de literatura española c temporánea, Anthropos, Barcelona, 1989.

${ }^{8}$ ROcc, 8 (1925), 358-377.

${ }^{9}$ En las citas de estos poemas de Moreno transcribo tal cual la ortogra de este nombre. Sin embargo, en su obra Lo mexicano en las artes plásticas (19 aparece como Xochipilli. 
ciones. Si esta acción simbólica lo aproxima al Saturno del Viejo Mundo, el mito azteca va más allá. Xochipilli usa careta: ludismo y hieratismo; creación y destrucción; Eros y Tánatos; presencia y ocultación conforman esa plurivalente y enigmática figura ${ }^{10}$.

Las canciones consisten en dieciocho poemitas cuya estructura, lenguaje y temas son engañosamente simples, como correspondiendo a un diosecillo juguetón. Pero al igual que la inmutable careta de Xochipilli oculta su verdadera faz, los poemas, en su sencillez y diafanidad, constituyen una máscara de difícil sondeo. La frase de Octavio Paz, "la máscara y la transparencia", (Corriente alterna), parafraseada, vendría al caso: en esa transparencia poética hay un enmascaramiento. Xochipilli y su máscara sirven al yo poético para manifestarse sin dársenos por completo, plantearse y compartir incógnitas. Es evidente una temática tradicional: lo eterno y lo perecedero; la brevedad de la vida; la piedra y la flor como emblemas. Los poemillas bordean lo aforístico y lo esquivan, lindan con lo sentimental sin caer en ello, reflexión y ludismo parecen cancelarse mutuamente. Es un conjunto difícil de descifrar: la ironía lo preside.

En otros poemas de este periodo, Moreno va de la nostalgia a la melancolía y al abatimiento. Aún cuando su tardía paternidad parece abrirle una esperanza, expresa sus reservas: "hago esta flor sencilla/en un vaso muy joven./Soy un loco". ("Coloquio paternal"). En otro poema, "La cara completa", se lee: "Como la cara no se termina hasta la muerte,/no te preocupes tanto del espejo $[\ldots] /$ Cuando se termine tu cara,/tendrás en ella tu vida, /tu vida y tu muerte". El epígrafe a las canciones a Xochipilli las explica sólo en parte; la expresión adverbial del comienzo impide una certidumbre total: "Tal vez haya escrito las canciones a Xochipili porque algo en el fondo de mi alma me decía que me iba saliendo ya la careta [cursivas mías] que le[s] sale a los viejos, la rigidez facial que por lo visto se exige en el seno de la tierra'. Pudiera aventurarse que la vuelta al poema corto como vehículo expresivo busca una compensación: recuperar un ritmo flexible, juvenil. Moreno Villa había cultivado con acierto

${ }^{10} \mathrm{El}$ diosecillo asoma también en dos poemas del poeta mexicano Carlos Pellicer: "Discurso por las flores" (Subordinaciones, 1949) y el soneto "Para El Xochipilli del pintor Correa Zapata", fechado en 1964. Del primero son estos penetrantes versos: "El pueblo mexicano tiene dos obsesiones:/el gusto por la muerte y el amor a las flores". Allende el mar, Xochipilli figura en la conocida novela de Carmen Laforet, $N a d a$ (1945) como inspirador de la elaboración artística de uno de los personajes (cap. 4). 
esa forma hacía años. El propio Cernuda lo aplaude: "Creo que una de lás pruebas de un poeta consiste en la posibilidad de canto; y en dicho volumen [Canciones, 1924] lo mismo que en todos los del autor [...] hay canciones llenas de gracia alada", y agrega que en los poemas a Xochipilli "el tono ligero de la canción reaparece en su obra otra vez, con la gracia de siempre y además, entre líneas, con cierta gravedad". Andando el tiempo, Juan Rejano comenzará su "Apunte de José Moreno Villa” (1950): “Te quedas para siempre troquelado/en la incontable brevedad: la copla,/así el perfil heroico en la moneda"11.

Una estudiosa de la literatura del exilio español, Marielena Zelaya Kolker, en un libro lleno de valiosas observaciones ${ }^{12}$, pone reparos a los poemas a Xochipilli del poeta español porque "promete y no llega a crear o recrear una emoción especial que ilumine una mitología o una estética específicamente mexicanas". Opinión estimable pero que no compartimos.

A lo ya adelantado, una quizás riesgosa incursión por lo antropológico y biográfico añade curiosas coincidencias. Sobre la máscara pre-colombina apunta Joseph Campbell: "Life is bu a mask worn on the face of death. And is death, then, but ano ther mask? "How many can say», asks the Aztec poet, «that ther is, or is not, a truth beyond?"'13. La opinión del conocido mito logista va ilustrada con dos imágenes de Xochipilli, la del códic vaticanense y la estatua del Museo de Antropología de México Nótese el doble interrogante con que concluye Campbell: la pro pia y la del poeta azteca. Por otra parte, se sabe que al cumplirs los cincuenta y dos años de cada ciclo apocalíptico, los antiguo mexicanos buscaban en las máscaras ocuitamiento protector con tra la destrucción por las fuerzas maléficas ${ }^{14}$. Moreno Villa, es tudioso del arte y costumbres mexicanas, podría haber andadi por sus cincuenta y dos años cuando concibió las canciones a Xc chipilli. Esos poemas surgen, pues, de esa confluencia que seña lábamos al principio, reiterada por Moreno en México: su flui

${ }^{11}$ La cita de Cernuda es de su "José Moreno Villa (1887-1955)", e Prosa completa, Barral, Barcelona, 1975, pp. 401-404. El poema de Rejano f gura en Moreno Villa: Iconografía.

12 Testimonios americanos de los escritores españoles transterrados de 1939, Cultı ra Hispánica, Madrid, 1985, pp. 46-48.

${ }_{13} \mathrm{~J}$. CAMPBell, The Mythic Image, Princeton University Press, Princetor 1974 , t. 2, p. 16.

${ }^{14}$ Véase Paul Westheim, Arte antiguo de México, F. G. E., México, 195 cap. 2. 
creador es "fijación de estados de espíritu por los que pasa el yo presionado por las circunstancias" 15 .

En La noche del verbo ${ }^{16}$ Moreno cuestiona insistentemente el ser y la existencia. De su "Epílogo" son estos versos, de una estremecedora certidumbre, directos, sin reticencias ni interrogantes:

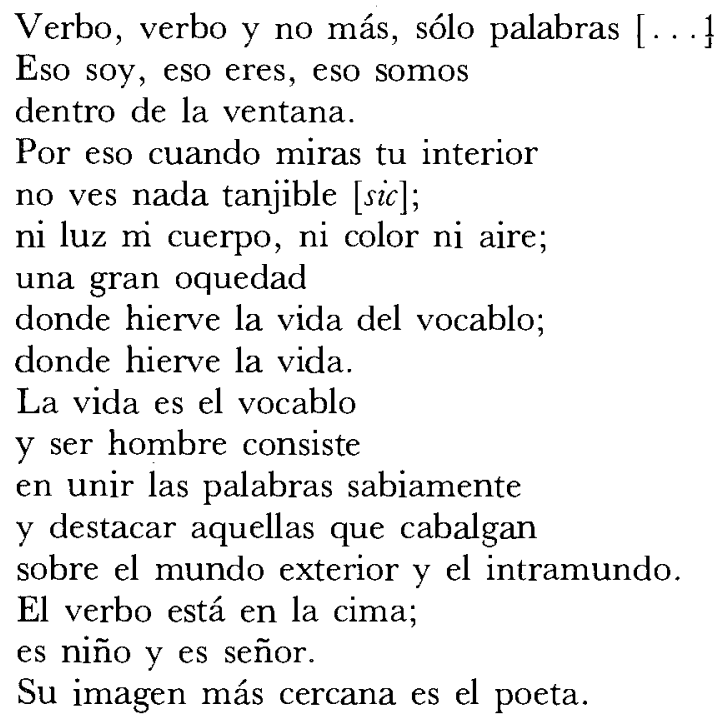

En las "Canciones a Xochipili" Moreno Villa se apropia, en mi opinión con éxito, del mito mexicano sin proponerse mitopoetizar como Bartra en su Quetzalcóatl. La máscara mítica, junto con la disposición estructural de las canciones, da al conjunto un hermetismo muy propio. No se escalonan hacia un rotundo final como el poema cernudiano; salpicadas como están de interrogantes, aun la abierta afirmación se escamotea (canción IX):

Tu careta es una ilusión,

Xochipili, como mi canción.

La canción, la careta y la flor son ilusiones multicolores.

15 "Algo sobre poesía", El Nacional, México, 13 de abril de 1952.

${ }^{16}$ Publicada en Tierra Nueva, México, 1942. 
En el conjunto, como las mariposas esculpidas en la estatua de Xochipilli, hay un aleteo, un abrir y cerrarse. Sin el cierre y final del poema de Cernuda, lo preside un orden paratáctico en que la coordinación invita a sucesivos reordenamientos que, a su vez, resultan en signos de diferentes sentidos.

Dice la voz lírica en "La noche del verbo" (1942): "Jamás encuentro tu semblante/jamás te veo, cara a cara, Yo". Y en las canciones al dios enmascarado el yo poético revela y vela su intimidad, no hay plena entrega. Sí un Moreno Villa esencial, decantado y acendrado a través de una máscara de engañadora transparencia. Los poemillas formulan y suscitan preguntas cuya respuesta ha de hacerla suya y aventurarla quien leyere. Al can. tar al dios azteca, el poeta ha adoptado la condición enigmátić de éste, su atractivo y su distancia. El poemilla final lo recalé con su giro inesperado a un conocido topos:

Esta es la flor no nacida,
la que no te obedeció,
Xochipili, la que dijo:
"nacer para un día, ino!"
y apretada en su capullo
se quedó.

4. Cernuda y Moreno Villa compartieron la condición de exilia dos y ambos recalaron en México. Recuerda el segundo, en s autobiografía Vida en claro (1944), su cuarto de Málaga con "un cama dorada, cuyo único adorno consistía en un escudo de $\mathbf{M} \dot{c}$ xico (¿por qué de México?)'. Y Cernuda admite sin ambages

En tu niñez y en tu juventud, ¿qué supiste tú, si algo supiste, c estas tierras, de su historia, que es una con la tuya? Curiosidar confiésalo, no tenías. Culpa tuya, sin duda; pero nada en torno pr día tampoco encaminarla. Lo que oías, cuando algo oías, frases pr líticas al uso, carentes por tanto de sinceridad y vacías de pens: miento; más era para matar toda curiosidad (Variaciones sobre ten mexicano [1952], “El tema').

"Quetzalcóatl"' precede al periodo mexicano de Cernud mientras que las "Canciones a Xochipili'" las escribió Morer Villa ya en México. Por distintos caminos, y en diferentes $\mathrm{m}$ mentos, estos dos poetas españoles encontraron en motivos mex 
canos instrumentos apropiados para creaciones señeras. Una vez más, la universalidad del artista verdadero rebasa las fronteras.

\author{
José AMOR y VÁZQUEZ \\ Brown University
}

\title{
APÉNDICE
}

\section{"QuetZalcóatL" *}

1. Yo estaba allí, mas no me preguntéis

De dónde o cómo vino ${ }^{1}$, sabed sólo

Que estuve yo también cuando el milagro,

No importa el nombre. Una aldea cualquiera

Me vio nacer allá en el mundo viejo ${ }^{2}$

$\mathrm{Y}$ apenas vivo me adiestré en la vida

Del miserable: hambre, frío, trabajo

Con soledad, ¿Quién le dio al fango un alma? ${ }^{3}$

2. Pero tuve algo más: el cielo aquel, el cielo

De la tarde en Castilla ( ${ }^{4}$ puro y vasto

Como ${ }^{5}$ frente de un dios que piensa el mundo.

Un mar de sangre y oro $^{6}$, cuya fiebre

$\mathrm{La}^{7}$ calmaba, toda azul, la noche honda

Con su perenne ${ }^{8}$ escalofrío de estrellas) ${ }^{9}$.

Me enseñó la lección digna del alma

Cuando lo contemplaba yo de niño

Sobre las bardas últimas $\mathrm{al}^{10}$ páramo.

3. Luego, como arenal sediento bebe el agua.

Así embebió mi mente ${ }^{11}$ las leyendas

De aquellos que pasaban a las Indias,

Perla sin par oculta en el abismo atlántico

* Lo tomo de Luis Cernuda, Poesía completa, Barral, Barcelona, 1977. Las notas se refieren a variantes respecto a la versión publicada en El Hijo Pródigo, México, 1943, pp. 152-154. (Me refiero a esta ed. con las siglas $E H P$.)

1 EHP: "vino:"

2 EHP: "viejo,"

3 EHP: "un alma al fango?"

${ }^{4}$ EHP: "“"

5 EHP: "Tal"

${ }^{6}$ EHP: " ", añadida

7 EHP; añadida

${ }^{8}$ EHP: "inmortal"

${ }^{9} E H P:$ " ")" añadido

10 EHP: "del"

11 EHP: "alma" 
Y por un hombre hallada, para adornar con ella, Poeta que regala su propio sueño vivo, Manos regias avaras y crueles.

4. Cuando vi un día las murallas rojas De la costa alejarse ${ }^{12}$, y yo perderme En la masa de agua, sentí ceder el nudo Que invisible nos ata a nuestra tierra ${ }^{13}$; Madrastra fuera, que no madre, y aún la quise. Comencé entonces a morir, mas era joven Y en ello no pensé, dándolo al olvido. Otras constelaciones velaron mi esperanza.

5. Pisando tierra nueva, de la mano el destino Me llevó llanamente al hombre designado Para la hazaña: aquel Cortés, demonio o ángel, Como queráis; para mi sólo un hombre Tal manda Dios, apasionado y duro. Temple de diamante, que es fuego congelado A cuya vista ciega quien le mira.

6. La ciudad contemplada desde el monte Desnuda la intención secreta de sus calles, Creídas al pisarla confusión sin rumbo; Así desnudó ${ }^{14}$ el tiempo aquellos años nuestros Preliminares, aunque perdidos parecieran: Su dispersión impulsó al aire la semilla Que caída en la tierra dio luego la cosecha.

7. Y el momento llegó cuando nos fuimos Por el mar un puñado de hombres; El mundo era sin límite, igual a mi deseo. Frente al afán de ver, de ver con estos ojos Que ha de cegar la muerte, lo demás, ¿qué valía? Mas este pensamiento a nadie dije Entre mis compañeros, a quienes hostigaba La ambición de riqueza y poderío.

8. Realidad fabulosa como leyenda alguna Allá nos esperaba, y nosotros la hallamos Tras sus cimas nevadas y sus lagos profundos: Un reino virgen cimentado en el oro y la esmeralda, Guardado por cobrizas criaturas recónditas Para las cuales Cristo fue nombre nunca oído. 
9. Astucia, fuerza, crueldad y crimen, Todo lo cometimos, y nos fue devuelto Con creces; mas vencimos, y nadie hizo otro tanto Antes, ni hará después: un puñado de hombres Que la codicia apenas guardó unidos Ganaron un imperio milenario.

10. Ya sé lo que decís: el horror de la guerra, Mas lo decís en paz, y en guerra ${ }^{15}$ calláis con mansedumbre. Nadie supo la guerra tan bien como nosotros, Ni siquiera los hombres allá en el mundo viejo Donde el emperador un trozo de pan daba Por conquistarle reinos: castillos en el aire, No bien ganados cuando ya perdidos.

11. Cuerpos acometí ${ }^{16}$, arrancando sus almas Apenas fatigadas de la vida.

Como el aire inconsciente las hojas de una rama; Destinos corté en flor, por la coròla Aún intacto el color, puro el perfume, ¿Hubo algún Garcilaso que mi piedra Hundiera bruscamente al fondo de la muerte? El reino del poeta tampoco es de este mundo.

12. Cuando en una mañana, por los arcos y puertas Que abrió la capital vencida ante nosotros, Onduló como ${ }^{17}$ serpiente de bronce y diamante Cortejo con litera trayendo al rey azteca, Me pareció romperse el velo mismo De los últimos cielos, desnuda ya la gloria, Sí, allí estuve, y lo $\mathrm{vi}^{18}$; envidiadme vosotros.

13. La masa nevada de terrazas y torres, Por la ciudad lejana de innumerables puentes, Se copiaba en el agua áurea de las lagunas Como sueño esculpido en luz gloriosa, Y encima refulgía la corona del cielo.

14. Pobre rey Moctezuma, golondrina Rezagada que sorprende el invierno, Mojada y aterida el ala ya sin fuerza ${ }^{19}$. Pero no es rey quien nace, y Cortés lo sabía.

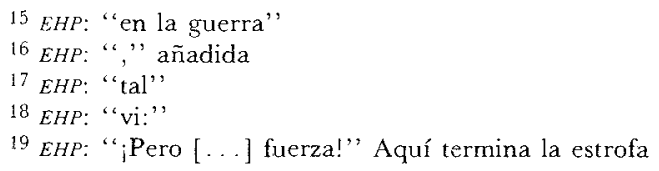


¿Por qué lo olvidó él luego, emulando con duques En la corte lejana, él, cuyos pies se hicieron Para besarlos ${ }^{20}$ príncipes y reyes?

Cuando él se abandonó también Dios le abandona.

15. Ahora amigos y enemigos están muertos $Y$ yace en paz el polvo de unos y de otros.

Menos yo: en mi existencia juntas ${ }^{21}$ sobreviven Victorias y derrotas que el recuerdo hizo amigas. ¿Quién venció a quién?, a veces me pregunto.

16. Nada queda hoy que hacer, acotada la tierra Que ahora el traficante reclama como suya Negociando con cuerpos y con almas ${ }^{22}$; Ya sólo puede el hombre hacer dinero o hijos. $\mathrm{Y}$ en un rincón al sol ${ }^{23}$ de este suelo, más mío Que lo es el otro allá en el mundo viejo, solo, pobre Tal vine, aguardo el fin sin temor y sin prisa.

17. Del viento nació el dios y volvió al viento Que hizo de mí una pluma entre sus alas. Oh tierra de la muerte, ¿dónde está tu victoria? 